\title{
BMJ Open Medical expenditure of women during pregnancy, childbirth and puerperium at the beginning of China's universal two-child policy enactment: a population-based retrospective study
}

To cite: Zang S, Zhao M, Zhu Y, et al. Medical expenditure of women during pregnancy, childbirth and puerperium at the beginning of China's universal two-child policy enactment: a population-based retrospective study. BMJ Open 2022;12:e054037. doi:10.1136/ bmjopen-2021-054037

- Prepublication history for this paper is available online. To view these files, please visit the journal online (http://dx.doi. org/10.1136/bmjopen-2021054037).

Received 03 June 2021 Accepted 12 February 2022

Check for updates

(C) Author(s) (or their employer(s)) 2022. Re-use permitted under CC BY-NC. No commercial re-use. See rights and permissions. Published by BMJ.

For numbered affiliations see end of article.

Correspondence to Professor Xin Wang; wxinsmile@qq.com

\section{ABSTRACT}

Objectives To describe and explore women's medical expenditures during pregnancy, childbirth and puerperium at the beginning of the universal two-child policy enactment in China.

Design Population-based retrospective study.

Setting Dalian, China.

Participants Under the System of Health Accounts 2011 framework, the macroscopic dataset was obtained from the annual report at the provincial and municipal levels in China. The research sample incorporated 65535 inpatient and outpatient records matching International Classification of Diseases, 10th Revision codes 000-099 in Dalian city from 2015 through 2017.

Primary and secondary outcome measures The study delineates women's current curative expenditure (CCE) during pregnancy, childbirth and puerperium at the beginning of the universal two-child policy in China. The temporal changes of medical expenditure of women during pregnancy, childbirth and puerperium at the beginning of China's universal two-child policy enactment were assessed. The generalised linear model and structural equation model were used to test the association between medical expenditure and study variables.

Results Unlike the inverted V-shaped trend in the number of live newborns in Dalian over the 3 studied years, CCE on pregnancy, childbirth and puerperium dipped slightly in 2016 ( $¥ 260.29$ million) from 2015 ( $¥ 263.28$ million) and saw a surge in 2017 ( $¥ 288.65$ million). The ratio of out-ofpocket payment/CCE reduced year by year. There was a rapid increase in CCE in women older than 35 years since 2016. Length of stay mediated the relationship between hospital level, year, age, reimbursement ratio and medical expenditure.

Conclusions The rise in CCE on pregnancy, delivery and puerperium lagged 1 year behind the surge of newborns at the beginning of China's universal two-child policy. Length of stay acted as a crucial mediator driving up maternal medical expenditure. Reducing medical expenditure by shortening the length of stay could be a feasible way to effectively address the issue of cost in women during pregnancy, childbirth and puerperium.
Strengths and limitations of this study

- This is a large population-based study with a randomly selected sample of women's medical expenditure during pregnancy, childbirth and puerperium.

- At the beginning of China's universal two-child policy enactment, maternal medical expenditure lagged after the rise in childbirth by 1 year.

- The study discovered that length of stay mediated the relationship between hospital level, year, age, reimbursement ratio and maternal medical expenditure

- Limited by data sources, other unevaluated factors could affect results.

- The setting was confined to only one city, limiting the generalisability of our findings to other regions.

\section{INTRODUCTION}

In the late 1970 s, to control the rapid population growth, the Chinese government introduced the one-child family planning policy. However, decades after enacting the one-child policy in China, population constraints have shifted from overpopulation to structural pressure stemming from skewed age distribution. To achieve demographic equilibrium, the universal two-child policy was implemented in January 2016. Its regulatory effect was very significant in the early stage after policy adoption. According to the National Bureau of Statistics of China, the newborn baby population saw a sudden surge in 2016, reaching a 17-year high since 2000, then edged down in 2017 and has taken a surprisingly sharp drop since 2018 . $^{1}$

Evidence suggests that fertility rates are dropping over time in most developed and many developing countries: close to half of the world's population lives in a country or area where lifetime fertility is below 2.1 live 
births per woman. ${ }^{2}$ As a result, a growing number of countries are rolling out government policies and programmes to increase fertility. ${ }^{3}$ The adjustment of fertility policy may have effects on the health system, and especially the health economy. Therefore, there is a compelling need to understand the probable health/social scenarios introduced by adjusting fertility policies.

There are many changes in pregnancy and maternity characteristics after adjustment of the universal two-child policy in China. The proportion of pregnant women over 40 years at high risk of many pregnancy complications and preterm birth increased after 2016. ${ }^{4}$ The prevalence of some age-related anomalies also ticks up since then. ${ }^{5}$ With the shift of decision-making regarding delivery mode, the caesarean delivery rate saw a rise among multiparous mothers versus a drop among nulliparous women. ${ }^{6}$ Maternity-related changes following fertility policy adjustments may present potential challenges to the health economy. Specifically, the changing mode of delivery, the number of births, obstetric complications and pregnancyassociated diseases may cause a mix of obstetric-related medical expenditure changes in this particular period. However, how the specific medical expenditure changes during the shift of the universal two-child policy lacks relevant research.

Previous research on China's universal two-child policy focused heavily on evaluating demographic changes, ${ }^{7}$ maternal health, ${ }^{8}$ birth-related health factors,${ }^{9}$ characteristics of pregnancy and delivery, ${ }^{10}{ }^{11}$ and adjustment of health services. ${ }^{12}$ A recent study reported that health expenditure in Chinese women of childbearing age was primarily incurred during pregnancy, delivery and puerperium. ${ }^{13}$ However, there is little research on the characteristics and influencing factors of women's medical expenditure during pregnancy, childbirth and puerperium, and especially during the universal two-child policy adjustment. Understanding the characteristics of medical expenditures related to delivery helps to better analyse the relevant socioeconomic issues and social phenomena during family planning policy adjustment.

The numbers of newborns in Dalian were 45714 in 2015, 69544 in 2016 and 60265 in 2017, enjoying a similar variation occurring in nationwide live birth numbers. ${ }^{14}$ The current study is set in Dalian (a coastal city in Liaoning province of China's northeast region) and examined the medical expenditure and factors associated with women's childbearing medical expenditure during pregnancy, childbirth and puerperium at the beginning of the introduction of China's universal two-child policy. This study aimed to analyse the reproductive medical economy issues surrounding China's universal two-child policy.

\section{METHODS}

The framework accounting for the current curative expenditure

This study described city-level medical expenditure based on the System of Health Accounts 2011 (SHA 2011). ${ }^{15}$
SHA 2011 is a universally applicable health financial framework that provides a tool to track health expenditure consumed by a country or region over 1 year or more. It also keeps tabs on such issues as where the money comes from and for what it is used. ${ }^{16}$ Therefore, it can capture financial trends related to healthcare. SHA 2011 separates current curative expenditure (CCE) from the capital structure in healthcare (eg, hospital buildings, ambulances and medical imaging machines). Accordingly, it reflects the characteristics of patients' direct health expenditure more accurately. SHA 2011 methodology can also provide an accounting for the CCE by clinical diagnosis and age groups. Under the framework of SHA 2011, this study delineated financing schemes, financial flows and the distribution in different age groups for women's medical expenditures during pregnancy, childbirth and puerperium from 2015 to 2017.

\section{Data sources}

The study data included two parts. The first part was the macroscopic dataset at the city level, which was obtained from the annual report at the provincial and municipal levels. These data were extracted from Dalian health statistical yearbook (2015-2017), Dalian health financial annual report (2015-2017), Dalian statistical yearbook (2015-2017), and Liaoning health and family planning statistical yearbook (2015-2017). The yearbooks and annual reports were obtained from the Health Commission of Dalian. The second part was the sample-level data on patients' medical expenses, demographic and clinical information, which came from sampled medical institutions in Dalian city.

\section{Sample method and sample size}

The sample institutions in this study were randomly selected from Dalian using multistage stratified sampling and the probability proportional to size method. The sample proportion was set at a ratio of $30 \%$. Five stages were included in this sampling procedure. In the first stage, the municipal-level hospitals in the city were picked by random sampling. In the second stage, six districts and three counties were extracted as sample areas based on economic level (gross regional product), medical conditions (health resources and health service level) and geographical location. For the third stage, districtlevel hospitals and county-level hospitals were randomly selected using the lottery method. The fourth stage was to choose streets from each selected district and extract communities (urban neighbourhood or rural village) from selected streets. The fifth stage was to determine primary healthcare institutions at all levels (ie, community health service centre, township health centre, community health service station and village clinic) in the sampled areas. Then the above institutions were randomly selected by the type under the preset sampling ratio of $30 \%$. The year 2015 was the first sampling year. To achieve the samples' full representativeness, the institutions were selected by expanding the numbers up to the nearest higher integers 
in each step if the computed value was not an integer. After the first sampling year, samples were drawn with the actual calculated values rounded off to the nearest integers in each sampling step. Once complete, 565, 496 and 456 medical institutions were sampled in 2015, 2016 and 2017, respectively. The data of women during pregnancy, childbirth and puerperium were collected from the sampled medical institutions.

The collected data included diagnosis, age, admission and discharge dates, length of stay, total and detailed expenditure of treatment (drug expenses, diagnostic and laboratory test expenses, surgery costs, nursing expenses, spending on blood, etc), out-of-pocket (OOP) payments, insurance type, reimbursement ratio, medical institution level and type of medical institution. All information that could be used to distinguish individuals' identity was coded and anonymised.

\section{The indicator system}

Health financing reflects the source of funds. Three sources of financing schemes constitute CCE in mainland China: public financing scheme, voluntary financing scheme and OOP payments. The public financing scheme is formed by social health insurance and government financing scheme. Voluntary health insurance programmes and enterprise financing plans make up the voluntary financing scheme. OOP payments are calculated by the total health expenditure minus insurance reimbursement.

\section{Quality control and data management}

Diagnoses were recorded according to the International Classification of Diseases, 10th Revision (ICD-10), and this study included ICD-10 codes O00-O99. The sample data were visually inspected by two researchers and subsequently cleaned using Microsoft Excel (Excel 2013, Microsoft Corporation, Redmond, Washington, USA) before data analysis. Missing, incomplete or unreasonable records were returned to the source institutions for verification and then resubmitted. For various reasons (eg, incomplete clinic or electronic register data, data entry errors), some abnormal or missing records still existed in the corrected database. After removing 950 unqualified records from the dataset, the final sample size was 65535 . Among these, 32390 records were from inpatient data, and 33145 records were from outpatient data.

\section{Patient and public involvement}

No patients or members of the public were directly involved in the study.

\section{Statistical analysis}

We compared CCE in different health financing schemes over the 3 years at the district level. The formula for calculating the CCE in this study was based on the manual co-edited by the Organization for Economic Co-operation and Development, the European Union and the WHO. ${ }^{15}$ For a more intuitive representation, a Sankey diagram was created to characterise the dynamic flow of CCE from different financing schemes to diverse health institutions.

For the sample dataset, descriptive analyses included medians and IQRs for continuous variables. Categorical variables were presented in terms of number and percentages. We explored the association between medical expenditure and study factors from all pooled data. The Shapiro-Wilk test was used to examine data normality. Results indicated that the patients' medical expenditure was not normally distributed. As inpatient expenditure accounted for the largest portion of CCE, this study analysed medical expenditure with inpatients in depth. Non-parametric Kruskal-Wallis $\mathrm{H}$ tests followed by DunnBonferroni post hoc pairwise comparisons were applied to compare inpatient expenditure among multiple groups by hospital level and type. Generalised linear models were used to evaluate the effects of the study variables on medical expenditure. Categorical variables were converted into sets of dummy variables. Optimal models were obtained using backward stepwise selection.

We conducted structural equation modelling to examine the simultaneous latent relationship between the study variables and medical expenditure. This study used $\chi^{2} / \mathrm{df}$, the goodness-of-fit index (GFI), the comparative fit index (CFI), the normed fit index (NFI), the relative fit index (RFI), the incremental fit index (IFI), the Tucker-Lewis index (TLI) and the root mean square error of approximation (RMSEA) to verify the model fit. According to conventional criteria, a good model fit is achieved with $\chi^{2} / \mathrm{df}$ below 3.00, GFI, CFI, NFI, RFI, IFI and TLI above 0.90, as well as RMSEA below $0.05 .{ }^{17} \chi^{2}$ is sensitive to the sample size. Although there is some decrease in dependency when it is divided by $\mathrm{df}, \chi^{2} / \mathrm{df}$ is also dependent on the sample size. ${ }^{18}$ When there is a large sample size, relatively loose confinement of $\chi^{2} / \mathrm{df}$ is acceptable. ${ }^{19} 20$

Statistical analyses were performed with SPSS Statistics for Windows, V.22.0 (IBM Corp); R, V.3.4.3 (The R Foundation; http://www.r-project.org); EmpowerStats software (www.empowerstats.com, X\&Y solutions, Boston, Massachusetts, USA); and AMOS software, V.20.0 (SPSS, Chicago, Illinois, USA). All statistical tests were two sided, and $\mathrm{p}<0.05$ was considered statistically significant.

\section{RESULTS}

CCE of women during pregnancy, childbirth and puerperium in Dalian from 2015 through 2017

During pregnancy, childbirth and puerperium, CCE for women in Dalian was ¥263.28 million in 2015, ¥260.29 million in 2016 and $¥ 288.65$ million in 2017 . The government financing scheme, voluntary financing scheme, OOP payments and CCE in 2016 dipped slightly from 2015 before bouncing up to a 3-year high in 2017. The social health insurance edged up in 2016 from its level in 2015 and saw a spike in 2017: ¥109.33 million in 2015, $¥ 110.85$ million in 2016 and $¥ 123.20$ million in 2017 . The ratio of OOP payment/CCE was on a downward trend 
Table 1 The health financing of women during pregnancy, childbirth and puerperium in Dalian city (million $¥$ )

\begin{tabular}{|c|c|c|c|c|c|c|c|c|}
\hline \multirow[b]{2}{*}{ Year } & \multirow[b]{2}{*}{ CCE } & \multicolumn{2}{|c|}{ Public financing scheme } & \multicolumn{2}{|c|}{ Voluntary financing scheme } & \multirow[b]{2}{*}{$\begin{array}{l}\text { OOP } \\
\text { payments }\end{array}$} & \multirow[b]{2}{*}{$\begin{array}{l}\text { Ratio of OOP } \\
\text { payment/CCE } \\
(\%)\end{array}$} & \multirow{2}{*}{$\begin{array}{l}\text { Ratio of public } \\
\text { financing } \\
\text { scheme/CCE } \\
(\%)\end{array}$} \\
\hline & & $\begin{array}{l}\text { Social health } \\
\text { insurance }\end{array}$ & $\begin{array}{l}\text { Government } \\
\text { financing scheme }\end{array}$ & $\begin{array}{l}\text { Voluntary health } \\
\text { insurance } \\
\text { programme }\end{array}$ & $\begin{array}{l}\text { Enterprise } \\
\text { financing plan }\end{array}$ & & & \\
\hline 2016 & 260.29 & 110.85 & 22.49 & 10.35 & 14.87 & 101.74 & 39.09 & 51.23 \\
\hline 2017 & 288.65 & 123.20 & 29.13 & 10.72 & 16.74 & 108.86 & 37.71 & 52.77 \\
\hline
\end{tabular}

CCE, current curative expenditure; OOP, out-of-pocket.

during the 3 studied consecutive years, at $39.26 \%$ in 2015 , $39.09 \%$ in 2016 and $37.71 \%$ in 2017 . An opposite trend was observed for the ratio of public financing scheme/ CCE (table 1). CCE of the 3 studied years totalled $¥ 812.22$ million, with the inpatient expenditure constituting a preponderance of $74.92 \%$, at $¥ 608.49$ million, and the outpatient expenditure accounting for the remaining $25.08 \%$, at $¥ 203.73$ million. The average exchange rates for 2015,2016 and 2017 were $¥ 6.23$, $¥ 6.64$ and $¥ 6.75$ per US dollar, respectively.

In this study, health institutions were categorised into five classes according to the scope of service: general hospital, maternal and childcare hospital, specialised hospital, traditional Chinese medicine hospital and basic medical institution (community health service centre, community health service station, township health centre and village clinic). The Sankey diagram in figure 1 illustrated the average CCE in 2015-2017 flowing from different financing schemes to diverse health institutions. Women during pregnancy, childbirth and puerperium had the highest expenditure, mainly in general hospitals (accounted for $59.00 \%$ ) and maternal and childcare hospitals (accounted for 28.59\%). Basic medical institutions accounted for only $1.30 \%$ of CCE. OOP payments accounted for $38.65 \%$ of the all-in cost.

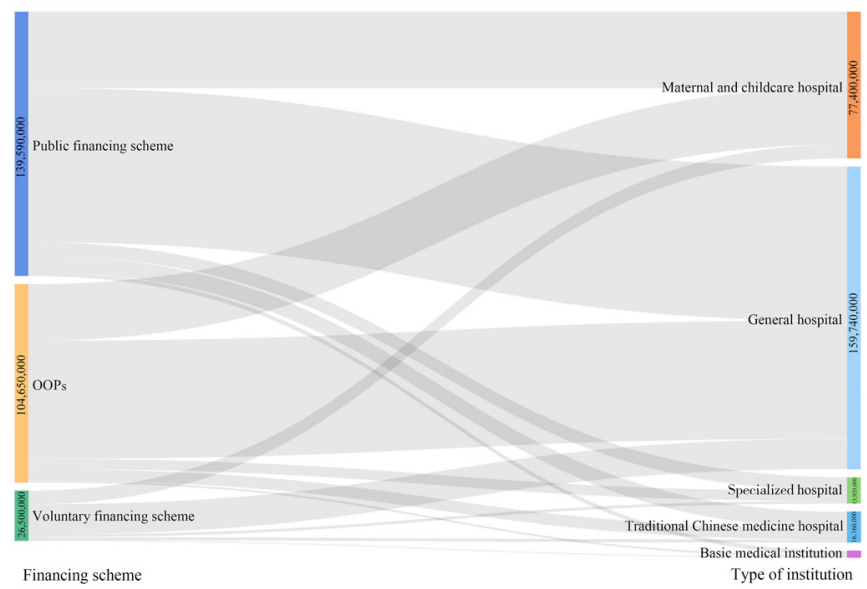

Figure 1 Sankey diagram of the average CCE in 2015-2017 flowing from different financing schemes to diverse health institutions. CCE, current curative expenditure; OOP, out-ofpocket.
CCE of women during pregnancy, childbirth and puerperium in different age groups

CCE on pregnancy, childbirth and puerperium climbed up from the age group 15-19 years, peaked in the age group 25-29 years, then dropped gradually at higher ages. CCE of all age groups was higher in 2017 than in 2015. For the group aged 35-54 years, CCE was higher in 2016 than in 2015. However, for the age group under 34 years, CCE was higher in 2015 than in 2016 (figure 2).

\section{Factors associated with inpatient expenditure}

As inpatient expenditure represented the majority of CCE, in-depth analyses of medical expenditure were conducted for inpatients. Univariate analysis revealed significant differences in inpatient expenditure by hospital level, type and year $(\mathrm{p}<0.001)$, with post hoc pairwise comparisons of all possible combinations being significant (all $\mathrm{p}<0.001$ ) (table 2).

A generalised linear model with medical expenditure as the outcome and with hospital level, hospital type, year, length of stay, reimbursement ratio and age as independent variables was run. All these factors were entered into the final model except the factor of age. The model was significant (Akaike Information Criterion $(\mathrm{AIC})=659179.430, \quad$ log-likelihood $=-329577.715$, $\mathrm{df}=12, \mathrm{R}^{2}=0.1260$ (adjusted $\mathrm{R}^{2}$ was 0.1257 ), and residuals $\mathrm{SD}=6353.006$ (Pearson $\chi^{2}$ normality test $\left.\mathrm{p}<0.001\right)$ ). Table 3 presents the econometric results of the generalised linear model for medical expenditure. Seeking medical help for pregnancy and childbirth in provincial

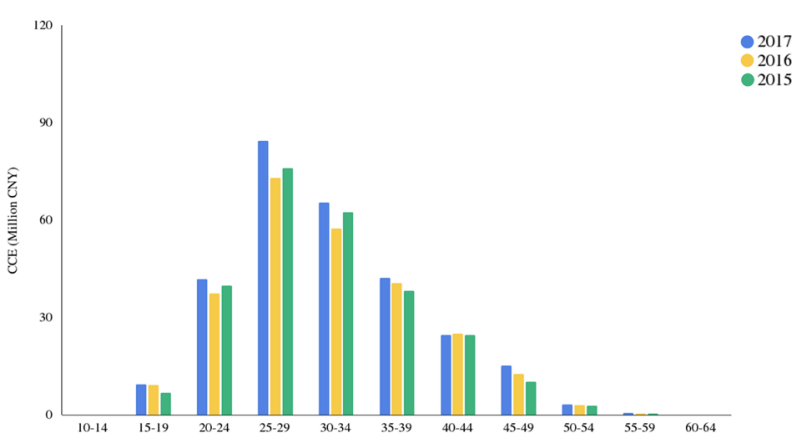

Figure 2 The proportion of CCE for each age group stratified by years. CCE, current curative expenditure; CNY, Chinese yuan. 
Table 2 Median expenditure and group differences for inpatients ( $N=32390)$

\begin{tabular}{|c|c|c|c|c|c|c|}
\hline Variables & $\begin{array}{l}\text { Variable } \\
\text { abbreviations }\end{array}$ & $\mathbf{n}$ & $\begin{array}{l}\text { Inpatient expenditure } \\
\text { Median (IQR) }\end{array}$ & $\mathbf{H}$ & $P$ value & $\begin{array}{l}\text { Post hoc test* } \\
\text { (adj. sig) }\end{array}$ \\
\hline Hospital level & $\mathrm{HL}$ & & & 183.175 & $<0.001$ & \multirow{5}{*}{$\begin{array}{l}\text { HL4>HL2 }(p=0.002) \\
\text { HL4>HL3 }(p<0.001) \\
\text { HL1>HL4 }(p<0.001) \\
\text { HL1>HL2 }(p<0.001) \\
\text { HL1>HL3 }(p<0.001)\end{array}$} \\
\hline Provincial & HL1 & 708 & 7468.01 (5362.22-12 642.35) & & & \\
\hline Municipal & HL2 & 16919 & $5262.20(3150.17-9053.13)$ & & & \\
\hline District & HL3 & 7924 & 5208.75 (3124.89-8885.33) & & & \\
\hline County & HL4 & 6839 & $5505.53(3850.45-6346.63)$ & & & \\
\hline Specialised hospital & $\mathrm{HT} 1$ & 3052 & 3673.14 (566.66-7320.34) & & & \multirow{4}{*}{$\begin{array}{l}\text {HT} 1>H T 2(p<0.001) ; \\
\text { HT3>HT2 }(p<0.001) ; \\
\text { HT4>HT2 }(p<0.001) ; \\
\text { HT2>HT1 }(p<0.001) ; \\
\text { HT3>HT1 }(p<0.001) ; \\
\text { HT4>HT1 }(p<0.001)\end{array}$} \\
\hline $\begin{array}{l}\text { Traditional Chinese medicine } \\
\text { hospital }\end{array}$ & HT2 & 2188 & 4145.63 (2883.82-5884.92) & & & \\
\hline Maternal and childcare hospital & HT3 & 10665 & $5375.32(3488.39-6419.05)$ & & & \\
\hline General hospital & HT4 & 16485 & 6053.01 (3634.96-9898.26) & & & \\
\hline 2017 & Y3 & 10741 & 6293.51 (4275.12-9984.97) & & & Y3>Y2 (p<0.001) \\
\hline
\end{tabular}

${ }^{*}$ Post-hoc test: Dunn-Bonferroni pairwise comparison.

or district hospitals, and in general hospitals, in the year 2017, and with longer hospital stay, was associated with higher expenditure.

\section{Modelling and model estimates}

We constructed a structural equation model to explore the direct and indirect relationship of variables on medical expenditure (inpatient and outpatient expenditure) (figure 3). The structural equation model demonstrated a good fit to the data with $\mathrm{GFI}=0.999, \mathrm{CFI}=0.991, \mathrm{NFI}=0.991$,

Table 3 Summary of the estimated coefficients for explanatory variables

\begin{tabular}{|c|c|c|c|c|c|c|}
\hline \multirow[b]{2}{*}{ Variables } & \multirow[b]{2}{*}{ Estimate } & \multirow[b]{2}{*}{ SE } & \multirow[b]{2}{*}{ t value } & \multicolumn{2}{|l|}{$95 \%$ Wald Cl } & \multirow[b]{2}{*}{$P$ value } \\
\hline & & & & Lower & Higher & \\
\hline Intercept & 8244.545 & 144.519 & 57.048 & 7961.286 & 8527.803 & $<0.001$ \\
\hline Provincial & 935.853 & 268.257 & 3.489 & 410.067 & 1461.638 & $<0.001$ \\
\hline Municipal & 115.775 & 107.034 & 1.082 & -94.012 & 325.561 & 0.279 \\
\hline County* & o† & & & & & \\
\hline \multicolumn{7}{|l|}{ Hospital type } \\
\hline Specialised hospital & -1851.923 & 134.112 & -13.809 & -2114.783 & -1589.064 & $<0.001$ \\
\hline Traditional Chinese medicine hospital & -2750.444 & 154.829 & -17.764 & -3053.910 & -2750.444 & $<0.001$ \\
\hline 2015 & -2865.814 & 85.143 & -33.659 & -3032.693 & -2698.934 & $<0.001$ \\
\hline 2016 & -4494.304 & 125.227 & -35.889 & -4739.748 & -4248.860 & $<0.001$ \\
\hline $2017^{\star}$ & $0+$ & & & & & \\
\hline Length of stay & 256.313 & 8.103 & 31.633 & 240.432 & 272.194 & $<0.001$ \\
\hline Reimbursement ratio & -607.055 & 144.483 & -4.202 & -890.241 & -323.869 & $<0.001$ \\
\hline
\end{tabular}

${ }^{*}$ Reference value.

†This parameter is set to zero because it is redundant. 


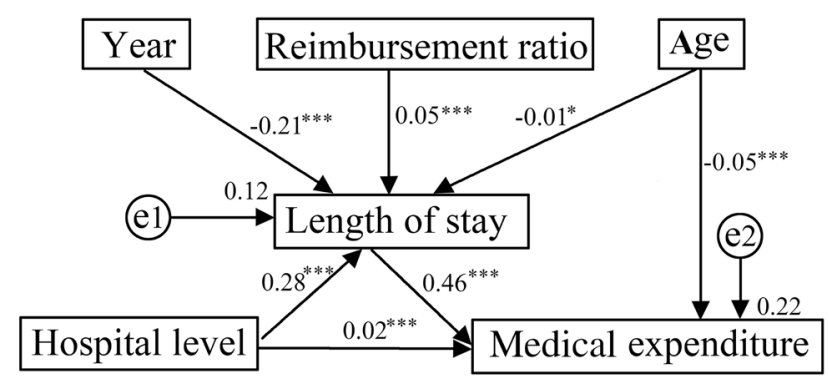

Figure 3 Path diagram of the structural equation modelling for medical expenditure.

RFI=0.977, IFI=0.991, TLI=0.978 and RMSEA $=0.020$. Considering that the structural equation model was run with a large sample size of 65535 , the values $\chi^{2}=221.983$, $\mathrm{df}=8$ and $\chi^{2} / \mathrm{df}=27.748$ were deemed acceptable. This model accounted for $21.80 \%$ of the total variance in medical expenditure. The length of stay was negatively associated with the year $(\beta=-0.21, \mathrm{p}<0.001)$ and positively affected by the reimbursement ratio $(\beta=0.05, \mathrm{p}<0.001)$. Length of stay $(\beta=-0.01, p=0.039)$ and medical expenditure $(\beta=-0.05, p<0.001)$ were negatively associated with age. Furthermore, length of stay $(\beta=0.46, p<0.001)$ and hospital level $(\beta=0.02, p<0.001)$ had direct positive paths on medical expenditure. Meanwhile, the hospital level directly weighed on the length of stay $(\beta=0.28, p<0.001)$. That is, the hospital level not only had a direct effect on medical expenditure but also had an indirect effect on medical expenditure through the length of stay.

\section{DISCUSSION}

This study demonstrated that China's universal twochild policy shift took a substantial weight on CCE on pregnancy, childbirth and puerperium. Based on the SHA 2011 framework, the financial flows were described systematically and allowed an accurate comparison of health expenditure across the years. We discovered an interesting phenomenon: unlike the inverted V-shaped trend in the number of live newborns in Dalian over the 3 studied years, CCE on pregnancy, childbirth and puerperium dipped slightly in 2016 from 2015 and saw a surge in 2017-indicating that CCE hike lagged 1 year behind the newborn hike. For women older than 35 years, CCE in each group showed an upward trend after 2016. Medical expenditure was associated with length of stay, hospital level, hospital type, year of treatment, maternal age and reimbursement ratio. The identified relationship between associated factors may help explore the reducing health expenditure and targets for policy adjustment.

One finding of this study was that while CCE on pregnancy, childbirth and puerperium climbed in 2017, the ratio of public financing scheme/CCE rose year by year, and the rate of OOP payment/CCE fell yearly. In response to the United Nations' Millennium Development Goals, many countries have made great efforts to improve maternal and children's healthcare. ${ }^{21}$ China has taken multiple actions to improve maternal health and reduce OOP payments. As public health expenditure is more likely than private health expenditure to affect a larger proportion of the population, ${ }^{22}$ the Chinese government implemented various measures in recent years, including but not limited to adding free antenatal screening and increasing maternity insurance coverage. From the health economic perspective of this study, structure of health financing is stepping in the right direction. Women of childbearing age may benefit.

There was a surge in the number of live newborns in 2016. ${ }^{14}$ Presumably, CCE was meant to follow the tide in the same year, but this study found that CCE edged down from 2015 and saw a hike 1 year later. Our other study confirmed that delivery CCE rose in the wake of the newborn surge, not 1 year later. ${ }^{23} \mathrm{CCE}$ in this study included the cost of delivery, prenatal and puerperium healthcare expenditure. Compared with delivery services, prenatal services are relatively cheap. ${ }^{24}$ Meanwhile, some free prenatal care has been incorporated into China's national basic public health service programme and has accordingly lowered antenatal medical expenditures. Advanced maternal age is considered a dominant risk factor for worse perinatal outcomes, ${ }^{25}$ which may increase the risk of medical expenditure in the particular study period. Accordingly, these factors may have conspired to contribute to the outcome.

In this study, CCE of women older than 35 years increased year by year, hinting that there was an increase in fertility behaviour and associated reproductive expenditure at the advanced-aged women at the initiation of China's universal two-child policy. This may be surmised from the following points. First, most of these women already had a child, and their wish for a second child was long overdue. Second, women's fertility is strongly linked to age. Women aged 35 years or older have significant uncertainty in their diminished reproductive potential, ${ }^{26}$ and may be more sensitive to the narrowing chance of childbearing. According to the theory of planned behaviour, a positive belief and attitude toward one thing would promote the intention to take action. ${ }^{27}$ When the women intend to have a second child, they will jump at the opportunity if the policy allows.

This study found a significant difference in medical expenditure according to the hospital level and type when concentrated on sampled inpatients. High-level hospitals are abundant in medical resources and have advanced technology and better medical teams. However, high-level hospitals' charges are higher, and the reimbursement ratio is lower than low-level hospitals in China. A previous study showed that Chinese patients' preference for hospitals is related to their trust level. ${ }^{28}$ The low quality of healthcare provided by some low-level hospitals undermines people's trust in those services, which subsequently render people to opt for high-level hospitals. Additionally, inpatients receiving treatment in general hospitals 
had higher medical cost than in other types of hospitals. General hospitals are usually provincial-level (or at least city-level) institutions, which generally represent higher quality medical care which other types of facilities fail to approach. Therefore, general hospitals handle most of the high-risk deliveries (eg, pre-eclampsia/eclampsia, placenta previa, placental abruption). Some severely ill patients are often referred from low-level institutions or initially choose high-level hospitals for more safety and professional treatment. ${ }^{29}$ Severe and deadly diseases are probably contributing to extended hospitalisation and increased cost.

This study determined that the path coefficient of age on medical expenditure and the length of stay was negative in the structural equation model. However, the path coefficient value was very low. Although various studies have demonstrated that medical costs increase with age for obstetric complications, ${ }^{30} 31$ the evidence does not line up neatly. A recent survey in childbearing women coincided with ours in finding that the length of stay after childbirth decreases with women's age ${ }^{32}$ This accordingly reduced delivery cost. Meanwhile, primipara usually experiences more anxious and prolonged delivery than multipara, ${ }^{33}$ which may extend the length of stay before and after birth. The disparities in the results mentioned above may come courtesy of the heterogeneity of the samples.

Our results also highlighted that the length of stay was a significant mediating variable in the relationship between year of treatment, reimbursement ratio, hospital level and medical expenditure. A study on obstetric complications showed that prolonged hospital stay leads to increased hospital expenditures. ${ }^{34}$ Length of stay is an important index to measure hospital quality and management, and various policies were adopted to shorten the length of stay in Chinese hospitals in the study period. ${ }^{35}$ Most high-level hospitals strive to cut the length of stay and create profits by accelerating patient turnover rates and using more advanced medical technology. ${ }^{36}$ Furthermore, our results were consistent with a longitudinal study showing that the trajectory of the length of stay was roughly dependent on that of the reimbursement ratio, with those enjoying a higher reimbursement ratio having longer stay. ${ }^{37}$ Inpatients with a high reimbursement ratio also had less OOP payments. Thus, they are more likely to increase the unnecessary length of stay or examinations. The result confirms that it is the right choice for China's cost-control policies to curtail the excessive length of stay and promote the leveraging effect of health insurance while maintaining care quality.

\section{Limitations}

This study has a few limitations. First, the study data were derived from Dalian city and thus may not be nationally representative. Second, due to limited sample information, we cannot probe into such factors as the severity of illness and treatment regimen, which might be associated with medical expenditure. Third, this study measured medical expenditure in the period of pregnancy, childbirth and puerperium with hospitals as the sampling units, without considering the continuity at individual level.

\section{CONCLUSIONS}

This study provides comprehensive evidence on health expenditure during China's family planning policy adjustment. Despite increases in CCE after the policy shift, the ratio of OOP payment/CCE was trending down, underlining the ongoing role of government assistance for the health economy. Furthermore, the rise in CCE on pregnancy, delivery and puerperium lagged 1 year behind the surge of newborns after introducing the universal two-child policy in China. Identifying the health expenditure trajectory and financing resultant may provide valuable direction for health policy. Length of stay played a crucial mediating role in adjusting women's medical expenditure, shedding light on the prospect of making it a breakthrough in health reform for containing medical expenditure.

\section{Author affiliations}

${ }^{1}$ School of Nursing, China Medical University, Shenyang, Liaoning, China

${ }^{2}$ Nursing Department, Tongji Hospital of Tongji Medical College of Huazhong University of Science and Technology, Wuhan, Hubei, China

${ }^{3}$ College of Health Management, Research Center for Health Development-Liaoning New Type Think Tank for University, China Medical University, Shenyang, Liaoning, China

${ }^{4}$ School of Public Health, Dalian Medical University, Dalian, Liaoning, China ${ }^{5}$ School of Nursing, Southern Medical University, Guangzhou, Guangdong, China

Contributors SZ-conceptualisation, methodology, statistical analysis, writing the original draft, review and editing. MZ-supervision, review and editing. YZhuestablished database, data curation and statistical analysis. YZhang —information support and formal analysis. YC - consulting literature and formal analysis. XWproject administration, conceptualisation, data collection and resources. All authors contributed, reviewed and edited the manuscript. XW is responsible for the overall content as guarantor.

Funding This work was supported by the Economy and Social Development Research Projects of Liaoning province (2022lslybkt-062), the Social Science Fund Project of Liaoning province (L21BSH017), the College Innovation and Entrepreneurship (Employment) Education Project in Guangzhou ((2019)15), and the Humanities and Social Sciences Research Planning Fund Project of the Ministry of Education (18YJAZH008).

Disclaimer The funders had no role in the study design and conduct; collection, management, analysis, and interpretation of the data; preparation, review, or approval of the manuscript; and decision to submit the manuscript for publication.

Competing interests None declared.

Patient and public involvement Patients and/or the public were not involved in the design, or conduct, or reporting, or dissemination plans of this research.

Patient consent for publication Not required.

Ethics approval Ethical approval was waived as the study did not require the participation of human subjects. The information was anonymous, and no data related to individuals were collected or were accessible. As a secondary analysis of existing data, ethics approval was therefore not necessary.

Provenance and peer review Not commissioned; externally peer reviewed.

Data availability statement Data are available upon reasonable request. Data are available upon reasonable request. Data are available from the corresponding author upon reasonable request.

Open access This is an open access article distributed in accordance with the Creative Commons Attribution Non Commercial (CC BY-NC 4.0) license, which 
permits others to distribute, remix, adapt, build upon this work non-commercially, and license their derivative works on different terms, provided the original work is properly cited, appropriate credit is given, any changes made indicated, and the use is non-commercial. See: http://creativecommons.org/licenses/by-nc/4.0/.

\section{ORCID iDs}

Shuang Zang http://orcid.org/0000-0001-7814-8011

Xin Wang http://orcid.org/0000-0001-7591-0103

\section{REFERENCES}

1 National Bureau of Statistics China Statistical Yearbook (online version), 1999-2019 [Internet]. Available: http://www.stats.gov.cn/tjsj/ ndsj/

2 United Nations, Department of Economic and Social Affairs, Population Division. World Population Prospects 2019: Highlights (ST/ESA/SER.A/423) [Internet]. Available: https://www.un.org/ development/desa/pd/sites/www.un.org.development.desa.pd/files/ files/documents/2020/Jan/wpp2019_highlights.pdf

3 Vollset SE, Goren E, Yuan C-W, et al. Fertility, mortality, migration, and population scenarios for 195 countries and territories from 2017 to 2100: a forecasting analysis for the global burden of disease study. Lancet 2020;396:1285-306.

4 Zhang $\mathrm{H}-\mathrm{X}$, Zhao $\mathrm{Y}-\mathrm{Y}$, Wang $\mathrm{Y}-\mathrm{Q}$. Analysis of the characteristics of pregnancy and delivery before and after implementation of the Twochild policy. Chin Med J 2018;131:37-42.

5 Zhang X, Chen L, Wang X, et al. Changes in maternal age and prevalence of congenital anomalies during the enactment of China's universal two-child policy (2013-2017) in Zhejiang Province, China: an observational study. PLoS Med 2020;17:e1003047.

6 Li H-T, Xue M, Hellerstein S, et al. Association of China's universal two child policy with changes in births and birth related health factors: national, descriptive comparative study. BMJ 2019;366:14680.

7 Fan SL, Xiao CN, Zhang YK, et al. How does the two-child policy affect the sex ratio at birth in China? A cross-sectional study. BMC Public Health 2020;20:789.

8 Yang T, Li N, Qiao C, et al. Development of a novel nomogram for predicting placenta accreta in patients with scarred uterus: a retrospective cohort study. Front Med 2019;6:289.

9 Zhao F, Xu Y, Chen Y-T, et al. Influence of the universal two-child policy on obstetric issues. Eur J Obstet Gynecol Reprod Biol 2020;252:479-82.

10 Liang $\mathrm{H}$, Fan $\mathrm{Y}$, Zhang $\mathrm{N}$, et al. Women's cesarean section preferences and influencing factors in relation to China's twochild policy: a cross-sectional study. Patient Prefer Adherence 2018;12:2093-101.

11 Wang E, Hesketh T. Large reductions in cesarean delivery rates in China: a qualitative study on delivery decision-making in the era of the two-child policy. BMC Pregnancy Childbirth 2017;17:405.

12 Yu X, Wang Z, Shen Y, et al. Population-based projections of blood supply and demand, China, 2017-2036. Bull World Health Organ 2020;98:10-18.

13 Wei H, Yang L, Sun Q. Analysis on the treatment costs for women of childbearing age in Sichuan under the "universal two-child" policy: based on SHA 2011. Chinese Health Economics 2019;38:41-4.

14 Dalian municipal bureau of statistics. Dalian's economic and social development statistics bulletins (2015-2017) [Internet]. Available: https://stats.dl.gov.cn/col/col3812/index.html

15 OECD, Eurostat, WHO. A system of health accounts 2011 edition. Paris: OECD, 2011.

16 Turner B. The new system of health accounts in Ireland: what does it all mean? Ir J Med Sci 2017;186:533-40.
17 Wu M. Structural Equation Modeling - Operation and application of AMOS. Chongqing: Chongqing university press, 2010.

18 Jon WH. The analysis of covariance structures: goodness-of-fit indices. Sociol Methods Res 1983;11:325-44.

19 Petrowski K, Schmalbach B, Jagla M, et al. Norm values and psychometric properties of the brief symptom inventory-18 regarding individuals between the ages of 60 and 95. BMC Med Res Methodol 2018;18:164.

20 Bentler PM, Bonett DG. Significance tests and goodness of fit in the analysis of covariance structures. Psychol Bull 1980;88:588-606.

$21 \mathrm{Kim} \mathrm{H}$, Novakovic U, Muntaner $\mathrm{C}$, et al. A critical assessment of the ideological underpinnings of current practice in global health and their historical origins. Glob Health Action 2019;12:1651017.

22 Novignon J, Olakojo SA, Nonvignon J. The effects of public and private health care expenditure on health status in sub-Saharan Africa: new evidence from panel data analysis. Health Econ Rev 2012;2:22.

23 Zang S, OuYang J, Zhao M, et al. Factors associated with child delivery expenditure during the transition to the National implementation of the two-child policy in China. Health Qual Life Outcomes 2021;19:30.

24 Njuguna J, Kamau N, Muruka C. Impact of free delivery policy on utilization of maternal health services in County referral hospitals in Kenya. BMC Health Serv Res 2017;17:429.

25 Napso T, Hung Y-P, Davidge ST, et al. Advanced maternal age compromises fetal growth and induces sex-specific changes in placental phenotype in rats. Sci Rep 2019;9:16916.

26 Lau BH-P, Huo R, Wang K, et al. Intention of having a second child among infertile and fertile women attending outpatient gynecology clinics in three major cities in China: a cross-sectional study. Hum Reprod Open 2018;2018:hoy014.

27 Ajzen I. The theory of planned behavior. Organ Behav Hum Decis Process 1991;50:179-211.

28 Duckett J, Hunt K, Munro N, et al. Does distrust in providers affect health-care utilization in China? Health Policy Plan 2016;31:1001-9.

29 Feng D, Zhang D, Li B, et al. Does having a usual primary care provider reduce patient self-referrals in rural China's rural multi-tiered medical system? A retrospective study in Qianjiang district, China. BMC Health Serv Res 2017;17:778.

30 Ratnasiri AWG, Parry SS, Arief VN, et al. Temporal trends, patterns, and predictors of preterm birth in California from 2007 to 2016, based on the obstetric estimate of gestational age. Matern Health Neonatol Perinatol 2018;4:25.

31 Bishai D, Bonnenfant Y-T, Darwish M, et al. Estimating the obstetric costs of female genital mutilation in six African countries. Bull World Health Organ 2010;88:281-8.

32 Kumar P, Dhillon P. Length of stay after childbirth in India: a comparative study of public and private health institutions. BMC Pregnancy Childbirth 2020;20:181.

33 Kong D, Bai J, Ma S, et al. Effects of dexmedetomidine hydrochloride on hemodynamics, postoperative analgesia and cognition in cesarean section. Exp Ther Med 2018;16:1778-83.

34 Zanconato G, Cavaliere E, Mariotto O, et al. Perinatal outcome of severe obstetric complications: findings of a 10-year hospital-based surveillance study in Italy. Int J Womens Health 2019;11:463-9.

35 Lanting L, Xia L, Jinlan F. Study on medical quality and efficiency under modern hospital management system: based on the analysis of average preoperative hospitalization days in a top tertiary hospital. Chinese Hospitals 2019;23:25-7.

36 Digenis C, Salter A, Cusack L, et al. Reduced length of hospital stay after caesarean section: a systematic review examining women's experiences and psychosocial outcomes. Midwifery 2020;91:102855.

37 Burn E, Edwards CJ, Murray DW, et al. Trends and determinants of length of stay and hospital reimbursement following knee and hip replacement: evidence from linked primary care and NHS Hospital records from 1997 to 2014. BMJ Open 2018;8:e019146. 